\title{
Fulminant myocarditis
}

\author{
Takatsugu Segawa, ${ }^{1}$ Yoh Arita, ${ }^{1}$ Tomomi Akari, ${ }^{2}$ Shinji Hasegawa ${ }^{1}$
}

${ }^{1}$ Department of Cardiology, Japan Community Healthcare Organization (JCHO) Osaka Hospital, Osaka, Japan ${ }^{2}$ Department of Pathology, Japan Community Healthcare Organization (JCHO) Osaka Hospital, Osaka, Japan

\section{Correspondence to}

Dr Yoh Arita,

arita-yo@osaka.jcho.go.jp

Accepted 13 January 2018

\section{DESCRIPTION}

A previously healthy 36-year-old man presented to the emergency department with dyspnoea after 3 days of fatigue and coughing. He experienced shortness of breath and had 8 hours of fever before admission. His body temperature was $38^{\circ} \mathrm{C}$. His ECG showed a wide QRS complex with no signs of acute myocardial infarction (figure 1). Echocardiography demonstrated oedematous left ventricular myocardium and severe, diffusely hypokinetic left ventricular wall motion with estimated ejection fraction of $30 \%$. Intra-aortic balloon pump (IABP) insertion was immediately performed for cardiogenic shock. Meanwhile, he experienced cardiac arrest with ventricular tachycardia. As cardioversion was unsuccessful, peripheral venous-arterial extracorporeal membrane oxygenation (va-ECMO) was initiated, with temporary pacemaker placement and dobutamine administration. Coronary angiography revealed normal coronary arteries. Shortly thereafter, he developed complete ventricular standstill, with no ventricular activity on the ECG and echocardiogram (figure 2 and video 1). Endomyocardial biopsy revealed massive lymphocytic infiltration (figure 3). Creatine kinase (CK) and CK-MB levels were elevated to $20261 \mathrm{U} / \mathrm{L}$ and $3485 \mathrm{U} / \mathrm{L}$, respectively. We diagnosed fulminant myocarditis (FM), an inflammatory process in the myocardium causing acute heart failure. Intravenous immunoglobulin ( $1 \mathrm{~g} / \mathrm{kg}$ for 2 days) and subsequent pulsed corticosteroid therapy ( $1 \mathrm{~g}$ for 3 days) were administered but were unsuccessful, and the patient died 16 days after admission.

Echovirus 9 infection was suspected by a more than fourfold increased antibody titre in serum sample collected on admission and 2 weeks later. Postmortem examination confirmed the final diagnosis of lymphocytic FM (figure 4), with lymphocytic infiltration and myocardial necrosis but no giant cell or eosinophilic infiltrates in the explanted heart.

FM is an uncommon disease, with clinical and histopathological features distinct from those of non-FM. ${ }^{1}$ Clinically, FM is characterised by acute

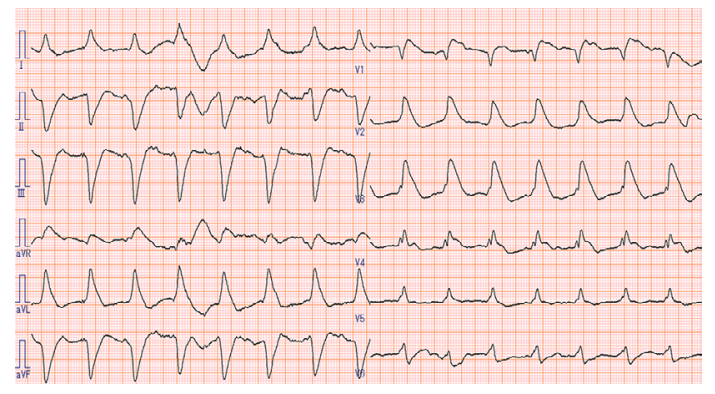

Figure 1 ECG findings on admission.

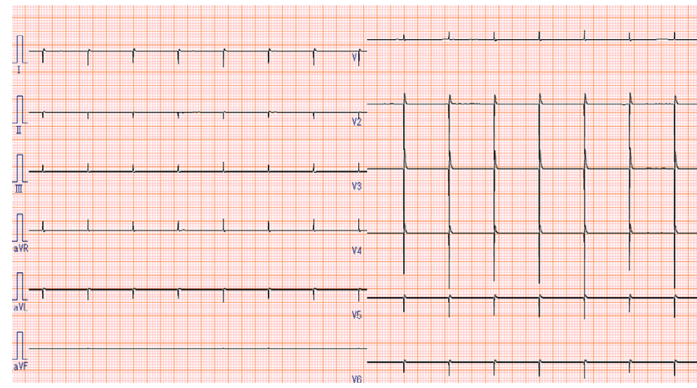

Figure 2 ECG showing ventricular standstill.

onset of severe haemodynamic instability, often in a previously healthy individual. The larger extension of inflammatory cells in the myocardium is associated with a worse in-hospital outcome of patients with lymphocytic FM. ${ }^{2}$ At initial presentation, however, these patients require aggressive haemodynamic support with positive inotropic drugs, IABP or other mechanical circulatory support such as va-ECMO. Endomyocardial biopsy is important to confirm the diagnosis of myocarditis and identify

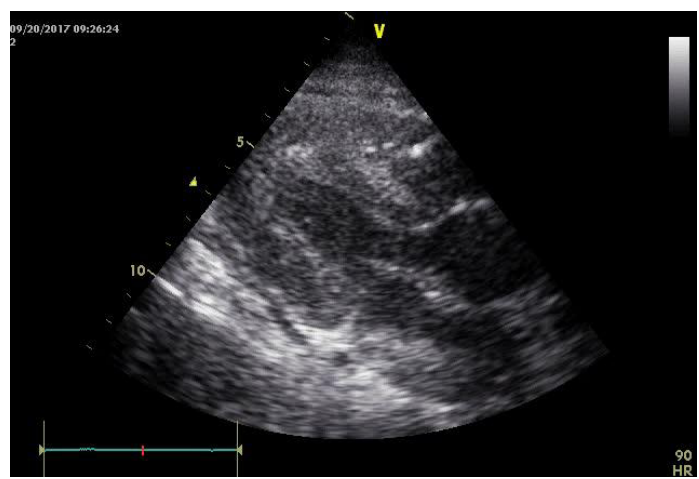

Video 1 Echocardiography showing ventricular standstill.

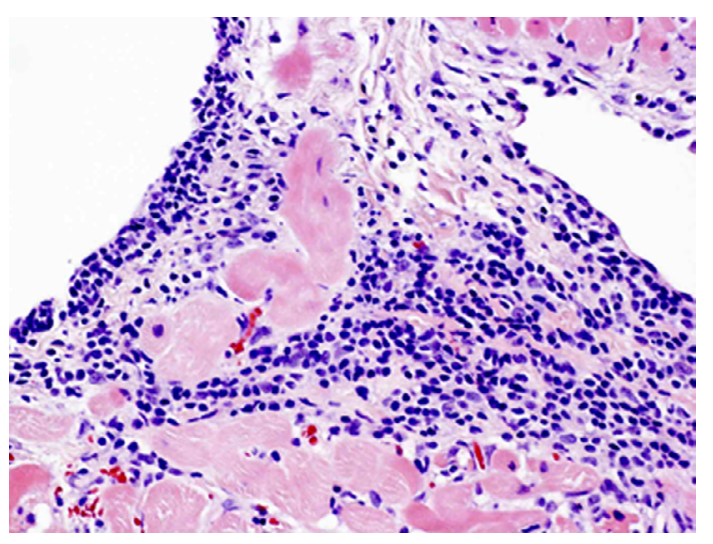

Figure 3 Endomyocardial biopsy from left ventricle revealed massive infiltration of lymphocytes. 


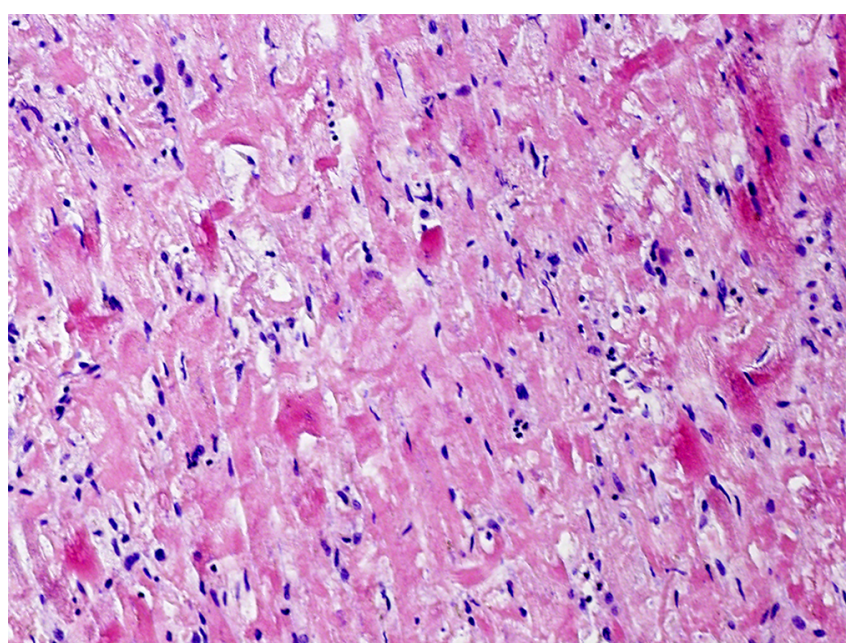

Figure 4 Postmortem examination confirmed the final diagnosis of lymphocytic fulminant myocarditis, with lymphocytic infiltration and myocardial necrosis but no giant cell or eosinophilic infiltrates in the explanted heart.

underlying aetiology and the type of myocarditis, including lymphocytic, giant cell and eosinophilic myocarditis. ${ }^{3}$ Currently, the only option for patients with end-stage or irreversible heart failure is heart transplantation; however, our patient was not a candidate because of his social background. The role of immunosuppressive therapies in patients with FM remains unclear, despite the putative deleterious consequences of immune activation that occurs in this illness. Indeed, our patient did not respond to these therapies.

This case serves as a reminder of the importance of FM and its management. While in specific forms of FM (ie, eosinophilic myocarditis, giant cell myocarditis and cardiac sarcoidosis)

\section{Learning points}

- Fulminant myocarditis (FM) is an uncommon disease, with clinical and histopathological features distinct from those of non-FM.

- Endomyocardial biopsy confirms the diagnosis of myocarditis and identifies the underlying aetiology and type of inflammation.

- Immunosuppressive treatments are not standardised because of lack of data on the treatment of lymphocytic myocarditis.

immunosuppressive therapy represents the mainstay of medical treatment, there is complete lack of standardised medical management for lymphocytic FM despite increasing evidence of the poor outcome.

Acknowledgements We would like to thank Dr. Chiaki Nakai, and Dr. YasuyukiYoshida for providing the image of endomyocardial biopsy.

Contributors YA, wrote this manuscript and involved in the patient's care. TS, involved in the patient's care. TA, performed histological examinations. SH, organised the patient's care.

Competing interests None declared.

Patient consent Next of kin consent obtained.

Provenance and peer review Not commissioned; externally peer reviewed. (c) BMJ Publishing Group Ltd (unless otherwise stated in the text of the article) 2018. All rights reserved. No commercial use is permitted unless otherwise expressly granted.

\section{REFERENCES}

1 Ginsberg F, Parrillo JE. Fulminant myocarditis. Crit Care Clin 2013;29:465-83.

2 Ammirati E, Cipriani M, Lilliu M, et al. Survival and Left Ventricular Function Changes in Fulminant Versus Nonfulminant Acute Myocarditis. Circulation 2017;136:529-45.

3 Pollack A, Kontorovich AR, Fuster V, et al. Viral myocarditis--diagnosis, treatment options, and current controversies. Nat Rev Cardio/ 2015;12:670-80.

Copyright 2017 BMJ Publishing Group. All rights reserved. For permission to reuse any of this content visit http://group.bmj.com/group/rights-licensing/permissions.

BMJ Case Report Fellows may re-use this article for personal use and teaching without any further permission.

Become a Fellow of BMJ Case Reports today and you can:

- Submit as many cases as you like

- Enjoy fast sympathetic peer review and rapid publication of accepted articles

- Access all the published articles

- Re-use any of the published material for personal use and teaching without further permission

For information on Institutional Fellowships contact consortiasales@bmjgroup.com

Visit casereports.bmj.com for more articles like this and to become a Fellow 